\title{
Teachers views about limitations / barriers of implementing teachers 'evaluation system in Undergraduate dental education in Bangladesh.
}

\author{
AminMS ${ }^{1 *}$,Ahmed $\mathrm{MS}^{2}$, Talukder $\mathrm{HK}^{3}$, .Khan $\mathrm{MI}^{4}$, Ansary $\mathrm{JA}^{5}$
}

\section{AFFILIATION:}

1. Dr.Md.Shoheilul Amin, Assistant Professor, Pioneer Dental College

2. Dr. Md. Salahuddin Ahmed, Associate Professor, Department of Prosthodontics, Pioneer Dental College

3. Professor Dr.Humayun kabir Talukder, Professor, Curriculum Development \& Evaluation, Center for Medical Education (CME), Dhaka.

4. Professor Dr. Md Ismail Khan, Vice-chancellor, Chottogram Medical University

5. Dr. Jamil Ahsan Ansary, Assistant Professor, Pioneer Dental College

\section{Article info.}

Received: $2^{\text {nd }}$ Feb, 2018

Accepted: 13 May, 2018

Volume: 8, Issue-2 October, 2018

DOI: https://doi.org/10.3329/updcj.v8i2.40377

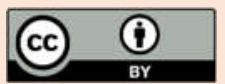

(C) Authors retain copyright and grant the journal right of first publication with the work simultaneously licensed under Creative Commons Attribution License CC - BY 4.0 that allows others to share the work with an acknowledgment of the work's authorship and initial publication in this journal.

https://creativecommons.org/licenses/by/4.0/

Publisher: Update Dental College, Dhaka, Bangladesh

Web: www.updatedentalcollege.edu.bd

E-mail: updcj@hotmail.com

$$
\begin{gathered}
\text { * Corresponding Author } \\
\text { Dr.Md.Shoheilul Amin } \\
\text { Assistant Professor, } \\
\text { Pioneer Dental College } \\
\text { ka-40/1 lichubagan road, Baridhara ,Dhaka } \\
\text { Email: shahel.dr@gmail.com } \\
\text { Phone-+880 1715026696 }
\end{gathered}
$$

\section{Citation}

AminMS, Ahmed MS,Talukder HK, Khan MI, Ansary JA. Teachers views about Limitations/barriers of implementing teachers' evaluation system in undergraduate Dental Education in Bangladesh. Update Dental College Journal. 2018 October; $8(2): 2-4$

\section{ABSTRACT}

Teachers are the main elements of dental education and naturally their performance has an essential role in health service efficiency. It is a series of activities and actions that are interconnected and relate to a specific purpose in the last two decades, the importance of teaching evaluation has been emphasized in higher education. Many medical and dental schools have searched for ways to effectively and constructively evaluate performances of their faculty members. The most common sources of evaluation data have been students, peers, and teachers themselves ${ }^{1}$. Teacher evaluation is often designed to serve two purposes- to measure teacher competence and to foster professional development and growth.

The goal of any effective evaluation process must be growth of good teacher ${ }^{2}$. Everyone wants to see our teachers grow and help them maximize their potential. Therefore the process is not one of "Got You" but rather one of facilitating growth. One of the qualities we need to have as educational leaders is that of humility and we should want to see our teachers succeed ${ }^{3}$.

This cross-sectional descriptive study was carried out among the teachers of three dental colleges of Dhaka city in last one year (2010-2011). Data were collected by convenience sampling. One public dental college and two private dental colleges were chosen according to the convenience of the researcher.34 teachers participated the study $34(n-34)$ by semi structured self-administered questionnaire to explore their views regarding teacher's evaluation in undergraduate dental education. All the answers were recorded by writing and checked at the end of the interview.

\section{KEY WORDS:}

\section{Dental Education, Teacher's Evaluation}




\section{INTRODUCTION-}

Importance of teaching evaluation has been emphasized in higher education. Many medical and dental schools have searched for ways to effectively and constructively evaluate performances of their faculty members ${ }^{4}$. Teacher evaluation serves two purposes- to measure teacher competence and to foster professional development and growth ${ }^{2}$. By sharing professional knowledge and practices, teachers can become enlightened and gather a deeper understanding of what constitutes effective teaching. Teachers are capable of identifying directions for self-improvement and carrying out plans to improve their effectiveness. Being a professional teacher implies a moral commitment to exemplary practice which results in high levels of student learning .Clearly, an aim of evaluation should be to enable teachers to analyze their own teaching to identify genuine needs and interests. With rapid change of science and technology time has come for dental education to fit in changing scenario. ${ }^{5}$

\section{METHODOLOGY}

This cross-sectional descriptive study was carried out among the teachers of three dental colleges of Dhaka city in last one year (2010-2011). Data were collected by convenience sampling. One public dental college and two private dental colleges were chosen according to the convenience of the researcher.34 teachers participated the study and semi structured self-administered questionnaire to explore their views regarding limitations/barriers of teacher's evaluation in undergraduate dental education. All the answers were recorded by writing and checked at the end of the interview. All the instruments were developed and finalized after pretesting outside of the study area.

\section{RESULT}

The result of the answer of questionnaires by teachers' analyzed by using SPSS soft wear package and was as follows. The teacher's views regarding teachers' evaluation were taken through self-administered semi structured questionnaire of selected dental colleges .Out of 34 teacher 15(44\%) from Pioneer dental College, 8 (23.5\%) from City Dental College, 11(32.4\%) from Dhaka Dental College. Most respondents 30 (88\%) gave their opinion in favor of implementation of teachers' evaluation in their institution, but only $6 \%$ responded negatively and $6 \%$ were not sure.

The views of the teacher about barriers to implement teachers' evaluations in dental institutes obtain from structured questionnaire are shown in the table.
Graph 1: Distribution of the respondent teachers as per their designation

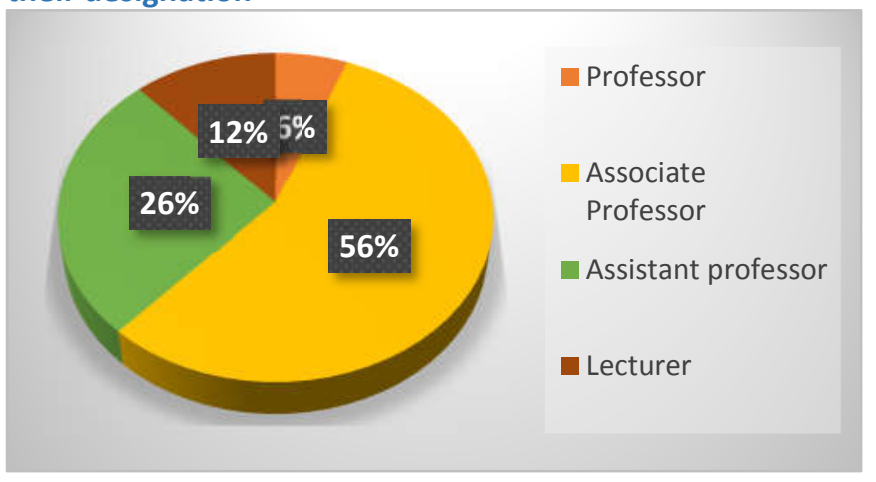

Graph no.1 Out of 34 respondents Professor was 2 (6\%), Associate Professor was 19 (56\%), Assistant Professors was 9 (26\%) and Lecturer was 4 (12\%).

Graph 2: Distribution of teachers by their opinion regarding the necessity of teachers' evaluation in dental education

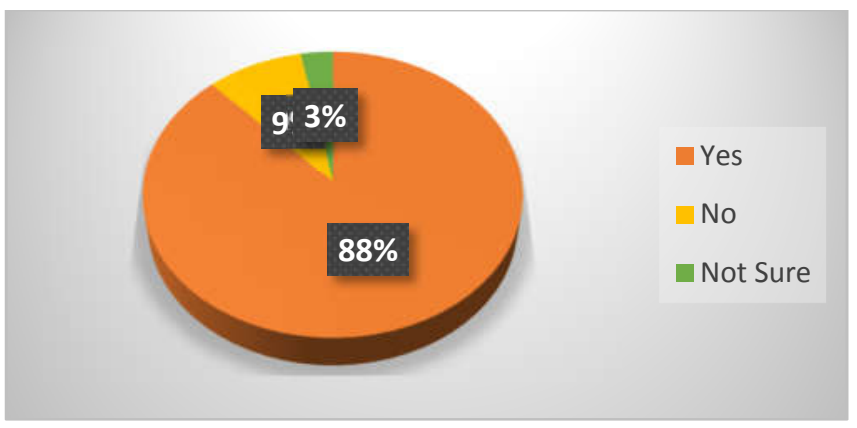

Graph no.2: have Shown that distribution of respondents regarding the necessity of teachers' evaluation in dental education .Out of 34 respondents, 30 (88 \%) gave opinion in favor, $3(9 \%)$ were not sure and $1(3 \%)$ were not in favor of teacher evaluation

Graph 3: Distribution of Teachers by their opinion regarding the necessity of implementing teachers' evaluation in their institutes

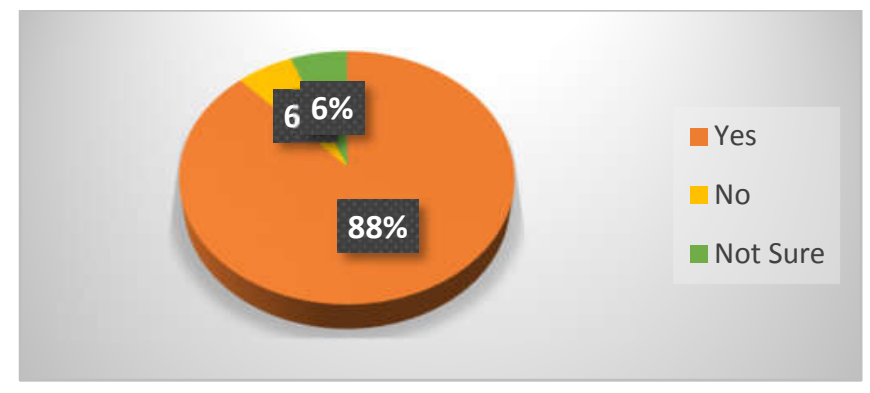

Graph no.3 has shown that out of 34 respondents, most respondents 30 (88\%) gave their opinion in favor of implementation of teachers' evaluation in their institution, but only $6 \%$ responded negatively and $6 \%$ were not sure 
Table 1-Distribution of the teachers by their opinion about the barriers to implement teachers' evaluations in dental institute.

\begin{tabular}{|l|l|l|}
\hline \multicolumn{1}{|c|}{$\begin{array}{c}\text { Barriers to implement teachers' } \\
\text { evaluations }\end{array}$} & Frequency & $\begin{array}{l}\text { Percent } \\
\text { (\%) }\end{array}$ \\
\hline Teachers are less motivated to be evaluated. & 34 & 100 \\
\hline $\begin{array}{l}\text { Administrators do not know how to perform } \\
\text { evaluation. }\end{array}$ & 32 & 94.1 \\
\hline $\begin{array}{l}\text { Teachers' evaluation will not be acceptable } \\
\text { by highest implementing authority politically. }\end{array}$ & 33 & 97.1 \\
\hline $\begin{array}{l}\text { Prejudice, corruption, bias etc. will hamper } \\
\text { proper teacher evaluation. }\end{array}$ & 34 & 100 \\
\hline $\begin{array}{l}\text { Teacher evaluation will impose extra cost in } \\
\text { the institutes. }\end{array}$ & 34 & 100 \\
\hline $\begin{array}{l}\text { It will require extra time to implement by the } \\
\text { faculties and administrators. }\end{array}$ & 32 & 94.1 \\
\hline It will require trained manpower. & 30 & 88.2 \\
\hline It will require extra manpower. & 31 & 91.2 \\
\hline
\end{tabular}

Table no.1 has shown that about the barrier to implement teachers' evaluations in dental institutes. All the teachers (34) agreed that, teachers are less motivated to be evaluated (100\%), prejudice, corruption, bias will hamper proper teacher evaluation (100\%), teacher evaluation will impose extra cost in the institutes (100\%).Other opinion are teachers' evaluation will not be acceptable by highest implementing authority politically (97.1\%), administrators do not know how to perform evaluation (94.1\%), it will require extra time to implement by the faculties and administrators(94.1\%), it will require trained manpower (91.2\%) and It will require extra manpower (88.2\%).

\section{DISCUSSION:}

The study explores the views of teacher about Limitations/barriers of teacher's evaluation in undergraduate dental education. It is apparent that most of the teachers noted that the potential use of teachers' evaluation lies in the fact that it will help to improve teacher's teaching ability and can be used to assess training need of the teachers ${ }^{4}$.. But the general purpose of teacher evaluation is to safeguard and improve the quality of instruction received by students ${ }^{5}$. Donald Medley described uses of formal teacher evaluation as (1) The Search for Great Teachers. (2) Inferring Teacher Quality from Student Learning; and (3) Examining Teaching Performance $^{6}$ There were some barrier to implement teachers' evaluations in both government and nongovernment institutes. Most of the teachers mentioned that teachers are less motivated to be evaluated and Prejudice, corruption, bias, etc. will hamper proper teachers' evaluation. Bradshaw \& Joyner mentioned ways for teacher evaluation such as gathering and using data on teacher performance, establishing feedback mechanisms, and including ways to meaningfully involve teachers in the process ${ }^{7}$.but in case of our country we are not motivated for evaluation even informal evaluation or peer evaluation. But best evaluator for teacher are the student ${ }^{8}$. By the opinion about teacher evaluation require extra time to implement by the faculties and administrator, will require trained manpower or extra manpower. But arrangement of training for evaluation will solve this problem easily.

\section{CONCLUSION}

Form discussion it is clear that teachers' evaluation is very much necessary as it is welcomed by most of the respondents, it will surely improve the current biased and imbalanced status of assessing teachers but there are some barriers which may affects evaluation process. We should overcome the limitations for ensuring a good healthy environment of study from which both the students and their teachers will be benefited.

\section{REFERENCES:}

1. Anderman, Smith, J. \& Belzer (1991).Teacher commitment and job satisfaction.

2. Akevy Greenblatt(2011) Teacher Evaluation and Teacher Professional Development.

3. Schiekirka S, Reinhardt D, Heim S, Fabry G, Pukrop T, Anders S et al. 2 Students perceptions of evaluation in development 16-18 undergraduate medical education: A qualitative study. BMC Medical Education 2012; 22: pp 1-21

4. Anderson (1996),MC,Med; 1996 Sep, 71(9)

5. Banda SS(2008), Student evaluation of teaching: a case study from School of Medicine (UNZA), Medical Journal of Zambia;volume-35:

6. Boyd, Ronald T. C(1989), Improving Teacher Evaluations. ERIC Digest; No. 111, 1989

7. Carrie mathers (2008) Improve instruction through effective teacher evaluation.

8. Copeland $\mathrm{HL}$, Hewson MG, Developing and testing an instrument to measure the effectiveness of clinical teaching in an academic medical center. Acad Med. 2000;vol-75. https://doi.org/10.1097/00001888200002000-00015 